\title{
The effect of salicylic acid on qualitative and quantitative characteristics of grafted grapevine seedlings
}

\author{
Natalia Pavlyuchenko ${ }^{1 *}$, Natalia Zimina ${ }^{1}$, Svetlana Melnikova ${ }^{1}$, and Olga Kolesnikova ${ }^{1}$ \\ ${ }^{1}$ All-Russian Scientific and Research Institute of Viticulture and Winemaking named after Ya.I. \\ Potapenko - branch of the Federal State Budget Scientific Institution Federal Rostov Agricultural \\ Scientific Centre (VNIIViV named after Ya.I. Potapenko), 166 Baklanovskiy avenue, 346421, \\ Novocherkassk, Rostov region, Russia
}

\begin{abstract}
While the production of grafted grapevine seedlings we studied the effect of treatment of copulation sections on rootstock vine cuttings with salicylic acid solution (SC) $\left(10^{-2}, 10^{-4}, 10^{-6}, 10^{-8}\right)$ on tissue regeneration, root formation, growth and development of shoots, leaf surface formation during the period of grafting stratification and on adaptation of seedlings in the field. In the experiment, we used grafted grapevine variety Cabernet Sauvignon, the rootstock - Berlandieri of Riparia Kober 5BB. The experiment was carried out according to a completely randomized scheme with triple repetitions (each repetition has 100 plants) in laboratory and field conditions. The results showed a reduction in the period of grafts' stratification in some variants, due to the activation of the process of callus tissue formation. At the same time, the use of salicylic acid stimulated the budding of the scion, the growth of shoots and the development of root system. Increased concentration of SC $\left(10^{-2}\right)$ inhibits the growth of shoots. The positive effect of SC on adaptive parameters was established.
\end{abstract}

\section{Introduction}

With the spread of phylloxera in European vineyards, a dangerous pest that affects the root system and the aboveground part of a bush, grafting is the only effective way to propagate grapevines. Despite the increase in the production of grafted seedlings, the issue of increasing the yield of grafted seedlings remains unresolved. The main reasons is incompatibility of graft and rootstock varieties belonging to different systematic species [1, 2]. Inoculation incompatibility can be defined as the inability to form a high-quality compound between two parts of a plant when all other requirements are met, such as technique, time, phytosanitary conditions, and environmental conditions $[3,4]$.

To overcome the incompatibility of the scion and rootstock, to accelerate the regeneration process, to stimulate or inhibit growth processes and root formation, physiologically active substances of various types are used in nursery production.

\footnotetext{
${ }^{*}$ Corresponding author: npavlyuchenko@yandex.ru
} 
Salicylic acid (SC) is a phenolic compound, a natural product of phenylpropanoid metabolism. Currently, SC is considered as an endogenous multifunctional bioregulator of phenolic nature, taking part in cellular signaling, growth processes, and the formation of adaptive reactions of plants [5].

A significant part of researches aimed at identifying the mechanisms of action of exogenous use of SC was carried out on annual crops (cucumbers, wheat, chickpeas, corn, etc.). Treatment with salicylic acid affects various processes occurring in a plant - stomatal closure [6], photosynthesis [7], plant productivity [8], flowering and fruiting [9], plants' growth and development and the soil microbiome [10]. The inducible role of SC in the formation of secondary roots has been established [11]. SC plays an important role in the formation of the structure of the root meristem and the architecture of the root system [12]. $\mathrm{SC}$ is actively used in culture in vitro to activate root formation, protect plants from diseases, improve the survival of meristems, and shoot formation [13].

The research is being conducted on the use of SC in viticulture. The use of SC to increase the resistance of vine to phytopathogens, by activating the immune system, is one of the promising areas of research. Pre-harvest treatment of table varieties with salicylic acid induces resistance to B. Cinerea, due to increased levels of phenolic compounds and the activity of antioxidant enzymes [14]. Pre-harvest spraying of bunches at the stages of small berry and berry softening is aimed at increasing the yield and improving the quality of products during harvesting and storage of seedless grape variety [15]. The effectiveness of SC use in order to increase the nutritional value has been proven. It was found that preharvest treatment with salicylates leads to an increase in the total acidity, the content of bioactive compounds and the activity of antioxidant enzymes in treated berries [16, 17].

The aim of the study was to assess the effect of salicylic acid on the processes of regeneration, root formation, growth, development and adaptation to biotic and abiotic stressors of grafted grapevine seedlings.

\section{Materials and methods}

\subsection{Biomaterial}

Grafted technical grapevine variety Cabernet Sauvignon was used in the study. The variety belongs to the ecological and geographical group of Western European grapevine varieties. France is the country of origin. The sum of the active temperatures from budding to harvesting is $3100-3300^{\circ} \mathrm{C}$. Shoots are strong-growing. By the time of autumn frosts, the vine usually maturates by $85-90 \%$. The variety is not phylloxera-resistant.

Rootstock variety-Berlandieri $\mathrm{x}$ Riparia Kober 5BB. The variety is characterized by increased resistance to phylloxera, frost, lime, diseases, good compatibility with most grafted varieties without significant influence on their morphological characteristics. Bushes are strong-growing, shoots are 5-6 m long, vine maturation is up to $80 \%$.

\subsection{Experimental conditions}

The study was conducted in 2019 and 2020. The experiment was set in triple repetition with 100 grafts per each repetition. For bench graft, a grafting machine with an omega-shaped knife was used. The cuts on the apical part of the rootstock were treated with salicylic acid before joining the grafts, dipping the stalk for 2-3 seconds in the solution. The place of connection the scion and rootstock was twice covered with a composition that does not contain physiologically active substances. The stratification was carried out in an open manner in the chamber, the grafts were placed on a single-stage shelf with the substrate glauconite sand. The air temperature in the chamber at different stages of stratification 
varied in the range of $28 \ldots 29^{\circ} \mathrm{C}$, the air humidity in different periods of stratification varied in the range of $80 \ldots 99 \%$. Planting of grafts in the field was carried out in May on a black plastic film, the planting scheme was $0.20 \times 0.15 \mathrm{~m}$.

\subsection{Climatic conditions}

The climatic conditions during the experiment were typical for the city of Novocherkassk. The climate is continental. The sum of the average daily positive temperatures from the third decade of April to the frost is $3300-3400^{\circ} \mathrm{C}$. The area belongs to the zone of insufficient moisture, the annual precipitation is $530 \mathrm{~mm}$. The meteorological conditions were monitored using a meteorological station located in the area of the experiment.

\subsection{Soil conditions}

Soil type-ordinary chernozem, carbonate, medium-thick, heavy-loamy, on loess-like loams. The supply of available nutrients in the arable layer is characterized by the following values: mobile phosphorus-3.27 mg / kg, exchange potassium-591.6 mg/kg, nitrates-40.72 $\mathrm{mg} / \mathrm{kg}$. The humus content is $5.2 \%$. Ground water lies deep, at the boundary between the soil-forming and underlying rocks

\subsection{Research methods}

\subsubsection{Evaluation of the quality of the source material for vine grafting}

For grafting, mature cuttings of the scion and rootstock were used, having a diameter in the upper part from 7 to $12 \mathrm{~mm}$. The humidity of the cuttings is $52 \ldots 53 \%$. The safety of the buds of the grafted variety is $100 \ldots 90 \%$.

\subsubsection{Determination of the quality of bench graft after stratification}

Visual examination was made to determine the quality of intergrowth of grafting component, connection density, the volume of callus formed, and the state of buds on the scion. All the plants of the experimental variant were taken into account. Number of leaves (PCs), total leaf area $\left(\mathrm{sm}^{2}\right)$, length of shoots $(\mathrm{sm})$, diameter of shoots $(\mathrm{mm})$ were measured in all plants. The area of the leaf surface was estimated by the ampelometric method.

\subsubsection{Determination of the survival rate of graft on the site}

Determination was performed 1-2 months after planting. Rooted grafting is characterized by the appearance of a tendril on a shoot. On the experimental plots of each variant, the total number of planted grafts and rooted ones were calculated, and the percentage of survival rate $(\%)$ was calculated.

\subsubsection{Determination of the yield of grafted grape seedlings}

The yield of seedlings was calculated by the ratio of the number of planted grafts to the number of standard dug up seedlings (\%) for each variant.

\subsubsection{Assessment of the quality of seedlings}

The development of seedlings was assessed in 30 plants for each variant, taking into account: the number of leaves (PCs), total leaf area $\left(\mathrm{sm}^{2}\right)$, length of shoots $(\mathrm{sm})$, diameter of shoots $(\mathrm{mm})$. Determination of the maturity of annual shoots was carried out by morphological characteristics. After digging up 25 seedlings from each variant were 
measured to determine the total number of roots on base of cutting with distribution in 3 fractions: up to $1 \mathrm{~mm}, 1-3 \mathrm{~mm}$ and more than $3 \mathrm{~mm}$.

\subsection{Statistical data analysis}

Statistical processing was performed using the Excel table processor.

\section{Results and discussion}

\subsection{Effect of salicylic acid on graft intergrowth}

The formation of callus tissue between the grafted parts of a plant is the beginning of intergrowth, leading to the formation of vascular system between the grafting partners, and it is assumed that it determines the future compatibility reaction of the graft and rootstock varieties [2]. In the SC $1 * 10^{-2}, 10^{-4}$, and $10^{-6}$ variants, external signs of callus formation at the graft junction were noted on day 10 after the grafts were placed in the stratification chamber. In the SC $10^{-8}$ and control variants, the beginning of callus formation was noted on day 12. It can be assumed that the application of exogenous salicylic acid to the rootstock section stimulates the endogenous acid of the plant to form callus. 12 days after the placement of the grafts for stratification, in the variant with a concentration of SC $10^{-4}$ and $10^{-6}$, more than $80 \%$ of the grafts were characterized by active callus formation.

Differences in the rate of bud breaking were found between the treatment options. Relative to the control variant, budding was observed 2 days earlier in the SC $10^{-4}$ variant, $1 * 10^{2}$ and $10^{-6}$ on the 1 st day. In the SC $10^{-8}$ variant, the date of bud break coincided with the control variant.

The data of the grafts' survey obtained on the 22nd day of observation indicate the dependence of the callus formation and grafts development on the concentration of salicylic acid solution. Due to the fact that the stratification took place in an open way, under artificial light, an active growth of shoots was noted. The average length of a shoot varied from 7.9 to $10.5 \mathrm{sm}$, in the control $-11.3 \mathrm{sm}$ (Table 1).

Table 1. The effect of salicylic acid on the development of grafts during the stratification period.

\begin{tabular}{|c|c|c|c|c|c|c|}
\hline Option & 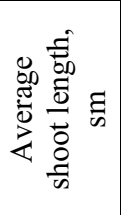 & 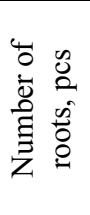 & 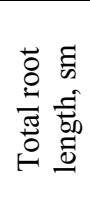 & 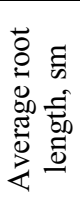 & 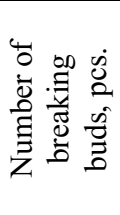 & 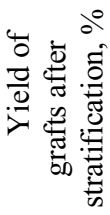 \\
\hline 1. Control & 11,3 & 6,3 & 36,5 & 5,8 & 1,5 & 94,0 \\
\hline 2. SK $10^{-2}$ & 8,7 & 4,2 & 21,3 & 5,1 & 1,4 & 80,0 \\
\hline 3. SK $10^{-4}$ & 9,5 & 2,9 & 14,4 & 5,0 & 1,6 & 87,3 \\
\hline 4. SK $10^{-6}$ & 10,5 & 4,2 & 26,4 & 6,2 & 1,5 & 93,3 \\
\hline 5. SK $10^{-8}$ & 9,9 & 2,1 & 10,4 & 5,1 & 1,4 & 75,3 \\
\hline $\mathrm{LSD}_{05}$ & - & 1,5 & 9,4 & - & - & - \\
\hline
\end{tabular}

It is believed that the formation of the root system in grapevine grafts occurs after planting in the field. However, during the passage of stratification on the nutrient substrate, which is glauconite, there is an early active formation of auxiliary roots, and by the time the stratification ends, a developed root system is formed. In the experiment, the average number of roots formed on one seedling varied from 2.1 to 4.2 pcs., in the control -6.3 pcs. $\left(\mathrm{NSR}_{05}=1.5\right)$. The most significant difference is found in the development of the root system. The indicator of the total root length, per graft, varied from $10.4 \mathrm{sm}$ in the SC10-8 
variant to $26.4 \mathrm{sm}$ in the SC $10^{-6}$ variant. In the control variant, the total length of the roots significantly exceeded the experimental variants and amounted to $36.5 \mathrm{sm}\left(\mathrm{NSR}_{05}=9.4\right)$, which indicates the inhibition of the SC process on differentiation and root growth, most clearly seen in the SC variant $10^{-8}$. However, the difference in the average length of one root in the variants was insignificant. Salicylic acid suppressed the development of root rudiments, which resulted in a significant lag in the formation of the root system.

There were no significant differences in the number of breaking buds. In the calculation per one eye, when treated with a solution of SC $10^{-4}$, 1.6 buds opened, $10^{-2}$ and $10^{-8}-1.4$ buds, in the control - 1.5.

In the experimental variants, the number of grafts with a circular callus and a breaking eye is lower than in the control one. The maximum yield $-93.3 \%$ was obtained when the cut was treated with a solution of SC $10^{-6}$, the minimum-75.3\% in the variant with treatment of SC $10^{-8}$, in the control variant $-94.0 \%$ (Fig. 1).

Monitoring of the development of grafts in dynamic showed that in the variant SK $10^{-4}$ and $10^{-6}$ formation of callus was more active, accession had uniform circular distribution of callus, without the influx, callus tissue was dense enough to reduce stratification for 2-3 days.

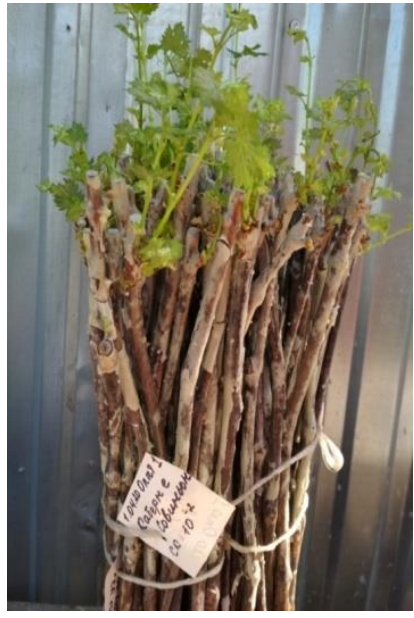

A

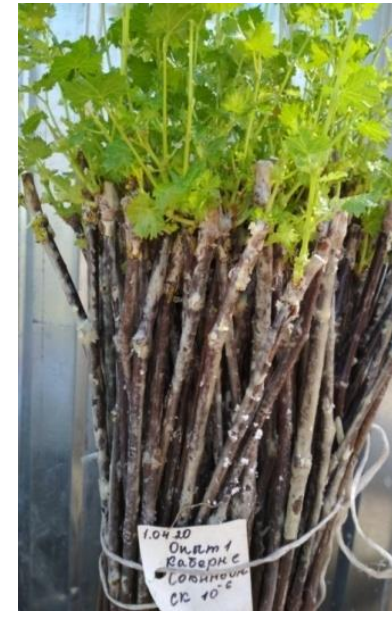

B

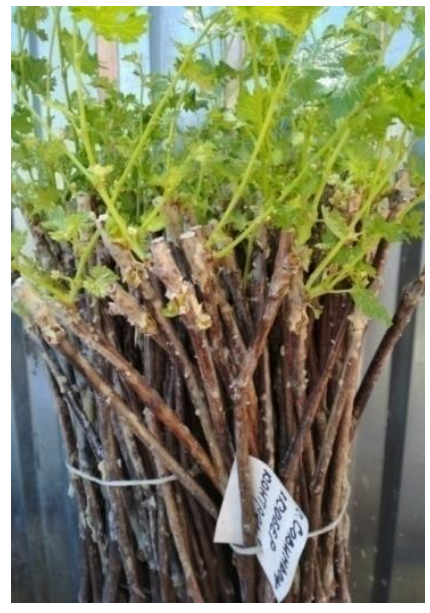

$\mathrm{C}$

Fig. 1. The effect of salicylic acid on regeneration process (Cabernet Sauvignon variety). A - Salicylic acid $1 * 10^{-2}$; B-Salicylic acid $1 * 10^{-6}$; C-control 0.0.

\subsection{Development of grafted seedlings in the field}

The graft intergrowth quality was evaluated one month after planting the grafts in the field. A significant difference in survival rate was marked. The highest indicator was noted in the variant of SC $10^{-2}-97.3$ and SC $10^{-8}-97.4 \%$ relatively to the planted ones. A low survival rate of $62.3 \%$ was established in the SC $10^{-6}$ variant, $18.7 \%$ less than the control variant $\left(\mathrm{NSR}_{05}=20.5\right)$ (table 2$)$. Thus, it was found that the variants with a lower yield of grafts after stratification had a high survival rate of grafts in the field.

The results of the studies showed a prolonged effect of salicylic acid on the survival and development of grafts in nursery. High survival rates of grafts were obtained in variants with salicylic acid concentration of $10^{-2}-97.3 \%, 10^{-4}-88.2 \%$ and $10^{-8}-97.4 \%$ relatively to the planted ones. In the SC $10^{-6}$ variant, the number of surviving plants is $18.7 \%$ less than in the control variant $\left(\mathrm{NSR}_{05}=20.5\right)$ (Table 2$)$. 
Table 2. Effect of salicylic acid on biometric parameters of grafted seedlings, Cabernet Sauvignon variety.

\begin{tabular}{|c|c|c|c|c|c|}
\hline Option & $\mathrm{SC} 10^{-2}$ & $\mathrm{SC} 10^{-4}$ & $\mathrm{SC} 10^{-6}$ & $\mathrm{SC} 10^{-8}$ & Control \\
\hline Survival rate, $\%$ & 97,3 & 88,2 & 62,3 & 97,4 & 81,0 \\
\hline Shoot length, sm & 62,7 & 57,5 & 72,6 & 48,7 & 52,1 \\
\hline Maturation of vine, \% & 66,0 & 69,5 & 58,2 & 74,0 & 56,0 \\
\hline Shoot diameter, mm & 5,1 & 4,4 & 4,6 & 4,4 & 4,4 \\
\hline Leaf surface area & 1061,4 & 707,3 & 1158,0 & 618,2 & 652,1 \\
\hline Area of one leaf, sm ${ }^{2}$ & 42,6 & 29,8 & 40,8 & 30,6 & 29,5 \\
\hline Number of leaves, pcs & 24,9 & 23,7 & 28,4 & 20,2 & 22,1 \\
\hline Internode length, sm & 2,5 & 2,4 & 2,6 & 2,4 & 2,4 \\
\hline Yeild of grafted plants & 44,0 & 37,3 & 33,3 & 35,3 & 32,4 \\
\hline
\end{tabular}

The assessment of biometric indicators of vegetating seedlings, carried out on day 120 during the period of active development, indicated differences in plant parameters. In the experimental variants, the average length of a shoot for the variants varied within 48.7-72.6 $\mathrm{sm}$. The best results were noted in the SC variants- $10^{-2}-62,7 \mathrm{sm}$, and $10^{-6}-72.6 \mathrm{sm}$. In the control variant $-52.1 \mathrm{sm}$.

The diameter of the seedlings' shoots correlates with the number of grafts per unit area $(\mathrm{r}=0.8)$ and was mainly $4.4-4.6 \mathrm{~mm}$. In the variant with a maximum salicylic acid content of $1 * 10^{-2}$, the shoot diameter is $5.1 \mathrm{~mm}$, which is $0.7 \mathrm{~mm}$ more than in the control indicator. The seedlings had a well-developed leaf apparatus that promotes the accumulation of nutrients in the shoots. The largest area of the leaf surface is marked in the SC variants $1 * 10^{-2}-1061 \mathrm{sm}^{2}$ and SC $1 * 10^{-}{ }^{6}-1158 \mathrm{sm}^{2}$, in the control $-652 \mathrm{sm}^{2}$. The correlation coefficient between the yield of grafted seedlings and the leaf surface area $\mathrm{r} \leq 0.3$ indicates a weak relationship. Consequently, the development of the leaf apparatus was more influenced by the SC. In the same variants, the maximum number of leaves per shoot was recorded-24.9 and 28.4 pcs., the area of one leaf -42.6 and $40.8 \mathrm{sm}^{2}$ and the length of the internode- 2.5 and $2.6 \mathrm{sm}$.

The state of the root system was evaluated after the end of the growing season of seedlings. The average number of roots varied by variants in the range of 12.4-17.4 pcs. per seedling, in the control -14.4 pcs. (fig. 2). A negative result, in comparison with the control, was obtained in the variant with a minimum concentration of SC- $1^{*} 10^{-8}$, the number of roots per seedling was 12.4 pcs., including roots with a diameter of more than $3 \mathrm{~mm}-0.6$ pcs., less than in other variants of the experiment. The average number of roots developed on one seedling did not correlate with the yield of seedlings $(r=0.2)$. 


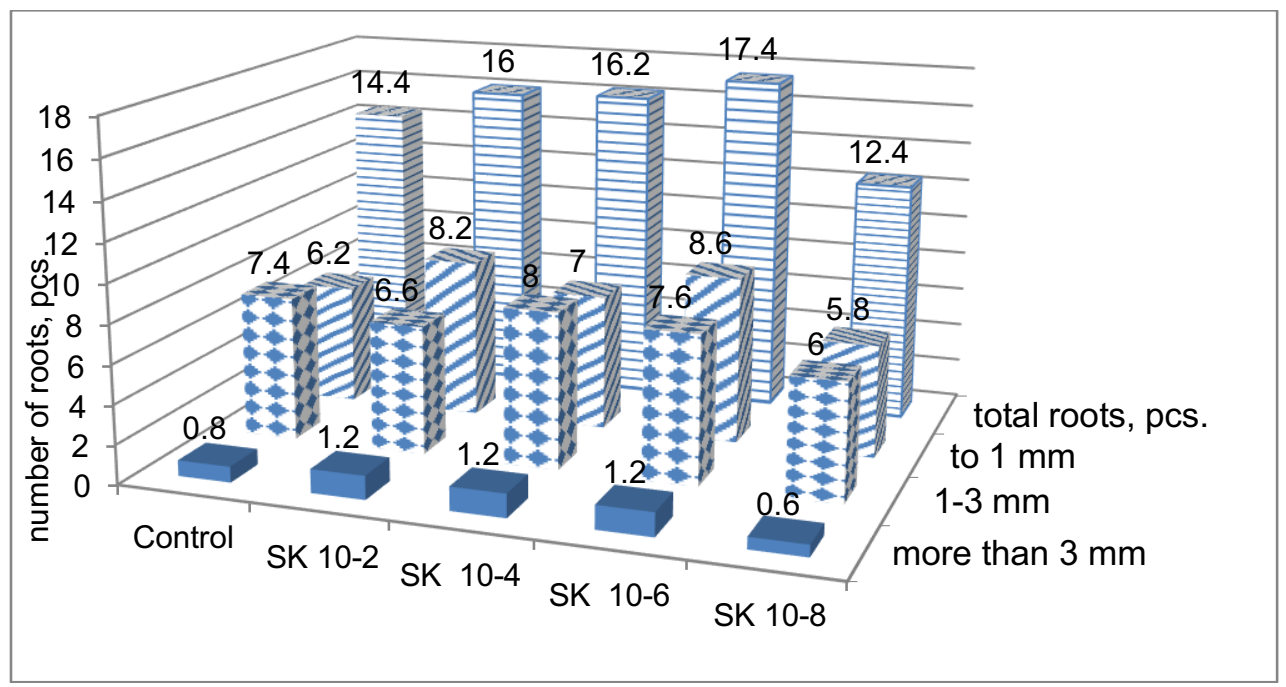

Fig. 2. Indicators of root system development of grafted seedlings. Treatment of the copulation section of the rootstock with salicylic acid solution.

\section{Conclusions}

The research proved that the use of salicylic acid in production of grafted grapevine seedlings at the initial stage - the connection of grafted components is effective. The dependence of indicators of shoot growth, differentiation and root growth on the concentration of salicylic acid solution is marked. Based on obtained results, the dependence of the process of callus formation and root formation on the concentration of salicylic acid solution was determined. A more active formation of callus tissue and a simultaneous bud breaking during the stratification of grafts was observed when the apical part of the rootstock was immersed in a solution with the concentration of $1 * 10^{-6}$. The inhibition of bud break and root system formation during the stratification period observed in plants treated with SC $1 * 10^{-2}$ and it had a positive effect on the process of field adaptation.

\section{References}

1. A. Pina, S. Cookson, A. Calatayud, A. Trinchera, P. Errea, Vegetable Grafting Principles and Practices (CABI Oxfordshire, Wallingford, UK, 2017), DOI: 10.1079 / 9781780648972.0132

2. A. Pina, P. Errea, H.J. Martens, Sci. Hortic. (Amst.), 143, 144-150 (2012), https://doi.org/10.1016/j.scienta.2012.06.017

3. M. Assunção, C. Santos, J. Brazão, J. E. Eiras-Dias, P. Fevereiro, BMC Plant Biol., 11, 19(1), 396 (2019), doi: 10.1186/s12870-019-1967-8

4. N. Pavlyuchenko, N. Zimina, S. Melnikova, O. Kolesnikova, E3S Web Conf., 210, 05011 (2020), DOI:https://doi.org/10.1051/e3sconf/20202100501

5. S. Hayat, B. Ali, A. Ahmad, Salicylic Acid: A Plant Hormone (Springer, Dordrecht, 2007), https://doi.org/10.1007/1-4020-5184-0_1

6. H. Pirasteh-Anosheh, A. Saed-Moucheshi, H. Pakniyat, M. Pessarakli, Water Stress and Crop Plants (2016), DOI: 10.1002/9781119054450.ch3 
7. T. Janda, G. Orsolya Kinga, R.Yordanova, G. Szalai Acta Physiologiae Plantarum, 36(10), 2537-2546 (2014), DOI: 10.1007/s11738-014-1620-y

8. Q. Fariduddin, S. Hayat, A. Ahmad. Photosynthetica, 41, 281-284 (2003), DOI: 10.17221/232/2012-PSE

9. C. R. Ngullie, R. V. Tank, D. R. Bhanderi, Advance Research Journal of Crop Improvement, 5(2), 136-139 (2014), DOI: 10.15740/HAS/ARJCI/5.2/136-139

10. Y. M. Koo, A. Y. Heo, H. W. Choi, Plant Pathol. J., 36(1), 1-10 (2020), doi: 10.5423/PPJ.RW.12.2019.0295

11. C. J. Dong, X. Y. Liu, L. L. Xie, L. L. Wang, Q. M. Shang, Planta, 252(5), 75 (2020), doi: 10.1007/s00425-020-03467-2

12. T. Pasternak, E. P. Groot, F. Kazantsev, W. Teale, N. A. Omelyanchuk, V. Kovrizhnykh, K. Palme, V. Mironova, Plant Physiology, 180(3), .00130 (2019), DOI: https://doi.org/10.1104/pp.19.00130

13. S. S. Hosseini, K Mashayekhi, M. Alizadeh, P. Ebrahimi, J. Ornam. Hortic. Plants, 1, 105-113 (2011), http://dx.doi.org/10.1007/BF03263276

14. M. E. García-Pastor, P. J. Zapata, S. Castillo, D. Martínez-Romero, F. Guillén, D. Valero, M. Serrano, Front Plant Sci., 11, 668 (2020), doi: 10.3389/fpls.2020.00668.

15. H. A. Marzouk, H. A. Kassem, Sci. Horti., 130, 425-430 (2011), https://doi.org/10.1016/j.scienta.2011.07.013

16. M. Oraei, S. Panahirad, F. Zaare-Nahandi, G. Gohari, J. Sci. Food Agric., 99(13), 5946-5952 (2019), doi: 10.1002/jsfa.9869

17. Abdulaziz M A Alrashdi, Al-qurashi Adel, Abeer awad mohamed, Saleh Ali Hassan Mohamed, Awad Alrashdi, Sci. Hortic., 220, 243-249 (2017), https://doi.org/10.1016/j.scienta.2017.04.005 